\title{
From global policy to local politics: The social dynamics of REDD+ in Asia Pacific
}

\author{
Andrew McGregor, ${ }^{*}+$ Michael Eilenberg¥ and Joana Borges Coutinho $\mathbb{1}$ \\ *Department of Geography and Planning, Macquarie University, NSW 2109, Australia. \\ †School of Geography Environment and Earth Sciences, Victoria University of Wellington, Wellington 6001, New Zealand. \\ Email: Andrew.mcgregor@mq.edu.au \\ ‡Department of Anthropology, Aarhus University, Moesgaard Alle 20, Hojbjerg DK-8270, Denmark. \\ Email: Michael@eilenberg.dk \\ ฯ School of International Development, University of East Anglia, Institute of Social Sciences, University of Lisbon, Lisbon \\ 1649-004, Portugal. \\ Email: J.Coutinho@uea.ac.uk
}

If there is one message that emerges from this collection of essays exploring how REDD+ (the Reducing Emissions from Deforestation and forest Degradation and enhancing forest carbon stocks and conservation programme) is unfolding in the Asia Pacific region, it is that geography matters. The theme recurs again and again as authors examine how this global initiative being developed by the United Nations Framework Convention on Climate Change (UNFCCC) and various grant and market initiatives is being negotiated across scale and space. The case studies show that no amount of planning within the offices and boardrooms of international environmental agencies and among expert communities can predict what will happen when their initiatives become embedded in particular localities. Contemporary and historic place-based politics, cultures, economies, ecologies and societies inevitably become tangled within and 'mess up' the best laid plans. Anyone who thought REDD+ would be a quick, cheap and simple approach to climate change mitigation has been sorely mistaken.

These essays emerged from a series of panels held at the EUROSEAS conference in Portugal in 2013. With REDD+ research still dominated by economists, physical scientists and practiceoriented researchers, the sessions provided a much needed space for critical social science researchers to discuss the emerging impacts of REDD+ on societies and cultures of the Asia Pacific region. Engaging anthropologists, geographers, political ecologists and a variety of other disciplines that employ ethnographic methods, the sessions were rich in qualitative analyses of the subtle and not so subtle consequences of the programme. What became immediately apparent is the agency of those engaging with the programme. Rather than being 'proponents', 'beneficiaries', 'opponents' or 'victims' of carbon conservation schemes, as some rather stereotyped debates about REDD+ imagine, we find layers of selective engagement as different groups approach the programme in ways that reflect their socio-ecological histories and interests. What began as a technical programme focused on mitigating carbon emissions has evolved into a much more dynamic set of social and political processes that is enabling and constraining for different sets of actors. As the Indonesian government now suggests, REDD+ is 'Beyond Carbon'. In these essays, the beyond carbon social dimensions of the programme, which for too long have been considered a 'co-benefit' in much of the technical literature, take centre stage.

What we get a feel for is the diversity of experiences being enabled through REDD+ within and across geographical scales. We also get a distinct Asia Pacific viewpoint on REDD+, where the socio-ecological contexts, relations and histories differ from those in other REDD+ regions, such as in Latin America and Africa. Indonesia's sprawling archipelago, for example, boasts high levels of forest cover which is being rapidly depleted for agricultural developments, particularly oil palm plantations (see Cramb and 
Curry, 2012 for a regional overview), and extractive industries like timber and mining. Forests are contested spaces as customary owners, forest-dependent communities, local and national authorities, and private interests compete for control of land and resources. The current political ecology favours deforestation, which Greenpeace (2013) estimates is the highest in the world, emitting immense amounts of carbon as peat and forest burns. Indonesia's poor record of forest conservation, alongside domestic commitments to reduce emissions by up to $41 \%$ has, somewhat ironically, made it an ideal location for REDD+ finance. So well, in fact, that Forest Trends (2015) estimates it has attracted over US\$2.4 billion in REDD+ finance, well beyond the $\$ 800$ million committed to Brazil, as the next highest recipient country. In contrast Vietnam, the second highest recipient in the Asia Pacific region has only received commitments of $\$ 88$ million. As such, Indonesia dominates REDD+ programming in the region, and it also dominates the papers in this collection. The lessons learnt from REDD+ in Indonesia, and the impacts it is having on people and places, may ultimately spell the success of failure of REDD+ as a potential climate mitigation mechanism.

Our papers begin at the international scale where Dixon and Challies (2015) explore how international private finance is mobilising around REDD+ in the context of Indonesia. The authors analyse the different motivations that are drawing investors to the programme and the types of finance that are emerging. While some forms of private finance exhibit the short-term profit-oriented characteristics that concern critical academics, others forms of private finance exhibit a much greater level of commitment to social and environmental factors. In contributing to the process of unpacking the 'black box' of private finance, the authors go beyond stereotypes of market-based environmentalism to consider how some forms of private capital can be oriented towards just and equitable outcomes while warning against more exploitative approaches.

Astuti and McGregor (2015) focus in on national scale processes, examining how REDD+ proponents, most notably the REDD+ Taskforce (Satgas REDD), have sought to mainstream the programme in Indonesia. The chal- lenge facing national authorities in the Asia Pacific region is immense, to shift forest politics away from entrenched debates between extractive industries, palm oil plantations and customary owners to a new economy oriented around an elusive and invisible element known as carbon. Through adopting a governmentality lens, the authors show how the adoption of participatory working groups, carbon languages, maps and participatory technologies have had some success in shifting forest debates at the national scale and in creating new opportunities for previously marginalised forest groups. However, considerable challenges remain if the existing political ecology driving deforestation is to be overcome.

The remaining papers focus on the experiences of REDD+ at more local scales. They provide a rich collection of stories that emphasise the unpredictability of the programme, and the importance of place in shaping how REDD+ is received, interpreted and implemented. The papers focus on what Anna Tsing (2005) refers to as the 'friction' that is generated when global processes encounter particular locales. Howell (2015) exposes the distance that has opened up between REDD+ developments at the national scale with the lack of progress at provincial and local levels. Drawing on findings from a case study of the UN-REDD programme in Central Sulawesi, Howell suggests a range of reasons for this failure that include the history of authoritarianism in Indonesia, a lack of capacity among local-level NGOs, ideological opposition to the programme, the limits of socialisation approaches to Free Prior Informed Consent, and the continuing influence of kinship relations on NGO and government activities. While acknowledging that REDD+ has enabled some national NGOs to 'take a seat at the table', there are many more social, cultural and political constraints to be overcome if the values and goals of REDD+ designers are to be influential and respected at more local scales.

Picking up on the important of place in shaping REDD+ programmes and the lack of engagement at local scales, Eilenberg (2015) examines REDD+ pilot projects in Kapuas Hulu district of West Kalimantan. He focuses on histories of contestation between local and national authorities, palm oil plantations and conservation groups. Historic and continuing 
concerns of elite capture, exclusion, confusion about programme goals, and competing land uses paint a bleak picture for REDD+ in the district. Villagers, who have long histories in dealing with top-down conservation and development initiatives, are exhibiting considerable resistance, choosing how and if they will engage with the programme. At this local scale, it is initiatives that improve local livelihoods, such as rubber plantations, that attract interest, rather than more abstract climate change goals.

Lounela (2015) and Mulyani and Jepson (2015) conduct their research in the neighbouring province or Central Kalimantan. They focused on the troubled Kalimantan Forest Carbon Partnership (KFCP) from which the major donor, the Australian government, recently withdrew. Both papers concern themselves with concepts of justice, providing insights into why the project has stalled. Lounela, like Eilenberg, shows how histories of engagement with conservation and development programmes have created mistrust towards externally driven initiatives and created active oppositional local organisations. Lounela's case study is based in Kapuas district which experienced the social and ecological devastation associated with former President Suharto's ill-fated Mega Rice Project (MRP). It also experienced problems of forest governance associated with post-Suharto decentralisation. Combined with previous failed conservation programmes, a climate of mistrust pervaded the KFCP with communities and practitioners promoting different understandings and approaches to social and environmental justice. Ultimately, the payment for an ecosystem services approach to economic justice that accompanies REDD+ in global negotiations did not translate well at the local scale. Community groups justified their resistance to the programme by promoting alternative visions of justice based on principles of equality, sharing and solidarity.

Mulyani and Jepson (2015) similarly focus on justice within Kapuas; however, they focus their attention on justice dimensions within the development of a Village Agreement between KFCP and local Dayak Ngaju villages. Once again, the MRP and failed conservation projects loom large in the environmental imaginaries of the participant communities, creating difficult socio-political terrains for project developers. Nevertheless, the authors find that consultation has been long and thorough, contributing to improved trust and social learning between stakeholders. In this sense, the Village Agreement marks a step forward in negotiations in the governance of forest land in Indonesia. However, consultation fatigue, frustrations and misunderstandings about project processes, village power relations, and differing opinions and access to decision-making processes all contributed to a rocky process. The authors argue that while constructive social learning can come out of Village Agreements, previous experiences with development projects will shape how people approach and enter these agreements. As such, global environmental programmes like REDD+ may be faltering due to the over-emphasis placed on spaces of high carbon value. Mulyani and Jepson's work suggests site selection should consider the impacts of previous development projects, where global encounters may have created socio-ecological landscapes that are more or less receptive to international programmes and are capable of pro-actively shaping new initiatives to suit local interests.

Howson and Kindon's (2015) paper takes a closer look at community dynamics of the nearby Sungai Lamandau project in Central Kalimantan. As the country's first communityinitiated REDD+ project, it makes a fascinating case study. They provide a rich understanding of how different types of local actors, such as farmers or women's groups, have sought to derive benefits from the project. Entrenched local power dynamics and social relations are shown to shape how people access and are excluded from benefits, with some using REDD+ to challenge or subvert existing structures and others using them to strengthen their positions. The authors show that finance, expertise, standards and developers only contribute part of the story of REDD+, and the agency of local groups has a substantial impact on how projects unfold. While 'equitable benefit sharing' is an admirable concept, this close reading of the Sungai Lamandau case shows how it is as illusionary as it is desirable.

The final three papers move out from Indonesia to look at REDD+ experiences in Cambodia, Papua New Guinea and the Pacific. Pasgaard's 
(2015) paper raises unsettling questions with regard to community consultation and reporting in the context of the Oddar Meanchey project in northern Cambodia. She traces how REDD+ is selectively translated by different actors who have an interest in producing a public script that heralds the project a success. The research shows how the REDD+ terminologies discussed by Astuti and McGregor (2015) introduced through national initiatives flow through reporting networks in exclusionary ways. Only some actors are invited to participate in monitoring and reporting, creating a self-reinforcing system. In such cases, REDD+ risks appearing to be positive to those outside the system, thereby increasing the value of the REDD+ credits, while leading to injustices and exclusions within it. Getting beneath the public script is part of the challenge for REDD+ researchers and something this collection contributes to.

Dalsgaard and Pedersen (2015) focus on REDD+ in Papua New Guinea where, despite being an enthusiastic early promoter of REDD+, national investment and interest in the programme are much less developed. In the PNG case, REDD+ projects face different challenges relating to the powerful logging industry, different community dynamics deriving from communal land ownership, and new legal processes that allow customary land to be leased out for agro-forestry purposes. In this context, the authors focus on the efforts of an NGO to harness REDD+ to protect the habitat and local livelihoods of rare tree kangaroos. REDD+ is providing some hope for securing habitat protection in a hard-to-access area; however, the introduction of portable sawmills, originally in aid of forest conservation, is providing new threats to the project. Dalsgaard and Pedersen's work reminds us that the goals of REDD+ are threatened not only by national policies, competing interests and community agency, but also by the affordances enabled by material technologies.

Our final paper is a Viewpoint written by a practitioner who has been working in the REDD+ space for many years. Weaver (2015) provides a welcome counterbalance to the previous articles by reminding us about the roots of REDD+ and why it has the potential to shift the dynamics of forest governance in a desirable way. Drawing on his experiences with Pacific
Island countries, Weaver presents some of the challenges facing REDD+, not from a local perspective, but from an international one. Even if REDD+ is able to find just and acceptable ways of pursuing climate mitigation, there are considerable barriers to be overcome before climate finance will flow. Weaver makes useful suggestions about how governments and some industries may be able to contribute to overcoming some of these barriers. Dixon and Challies (2015) have shown how social scientists can contribute to the types of issues Weaver is concerned about. Applying ethnographic skills to improve our understanding of the power relations, cultures, ecologies and social structures of international climate finance, by 'studying up' as Laura Nader (1974) long ago described it, is a task that needs doing.

As a whole, the papers trace some of the troubled pathways that REDD+ has taken throughout the region. They emphasise the importance of ethnographic research to understanding why global environmental initiatives rarely unfold in the way in which they are designed. If we are to better address the challenges of climate change, there needs to be better dialogues between critical academics and practitioners and a greater openness and awareness of the plurality of knowledge and values involved in human-environment relations (Castree et al. 2014; McGregor et al. 2014). Current instrumentalist approaches based on abstract models of human behaviour, in this case the use of economic incentives to shift human-forest relations, ignore socioecological histories, diverse place-based motivations and values, and pay too little attention to existing social, economic and political contexts. Quite simply, one size does not fit all. For programmes like REDD+ to work, they must emerge from genuine understandings and partnerships involving financiers, practitioners and participants - and they must be flexible enough to respond to different place-based concerns. We hope this issue contributes to this goal.

\section{References}

Astuti, R. and A. McGregor (2015) Governing carbon, transforming forest politics: A case study of Indonesia's REDD+ Task Force, Asia Pacific Viewpoint 56(1): $21-36$. 
Castree, N., W.M. Adams, J. Barry et al. (2014) Changing the intellectual climate, Nature Climate Change 4: 763-768.

Cramb, R. and G.N. Curry (2012) Oil palm and rural livelihoods in the Asia-Pacific region: An overview, Asia Pacific Viewpoint 53(3): 223-239.

Dalsgaard, S. and M. Pedersen (2015) The portable sawmill and other challenges to REDD+ in Papua New Guinea, Asia Pacific Viewpoint 56(1): 128-139.

Dixon, R. and R. Challies (2015) Making REDD+ pay: Shifting rationales and tactics of private finance and the governance of avoided deforestation in Indonesia, Asia Pacific Viewpoint 56(1): 6-20.

Eilenberg, M. (2015) Shades of green and REDD: Local and global contestations over the value of forest versus plantation development on the Indonesian forest frontier, Asia Pacific Viewpoint 56(1): 48-61.

Forest Trends (2015) Tracking Forest Finance - Indonesia. Forest Trends, from Website: http://reddx.forest -trends.org/country/indonesia/recipients

Greenpeace (2013) Down to Zero: How Greenpeace is ending deforestation in Indonesia, 2003-2013 and Beyond, Jakarta: Indonesia.

Howell, S. (2015) The Politics of Appearances: Some reasons why the UN-REDD project on Central Sulawesi failed to unite the various stakeholders, Asia Pacific Viewpoint 56(1): 37-47.

Howson, P. and S. Kindon (2015) Analysing access to the local REDD+ benefits of Sungai Lamandau, Central
Kalimantan, Indonesia, Asia Pacific Viewpoint 56(1): 96-110.

Lounela, A. (2015) Climate change disputes and justice in Central Kalimantan, Indonesia, Asia Pacific Viewpoint 56(1): 62-78.

McGregor, A., S. Weaver, E. Challies, P. Howson, R. Astuti and B. Haalboom (2014) Practical critique: Bridging the gap between critical and practice-oriented REDD+ research communities, Asia Pacific Viewpoint 55(3): 277-291.

Mulyani, M. and P. Jepson (2015) Social learning through a REDD+ 'village agreement': Insights from the Kalimantan Forests Climate Partnership (KFCP) in Indonesia, Asia Pacific Viewpoint 56(1): 79-95.

Nader, L. (1974) Up the anthropologist - perspectives gained from studying up, in D. Hymes (ed.), Reinventing Anthropology, pp. 284-311. New York: Vintage Books.

Pasgaard, M. (2015) Lost in translation? How project actors shape REDD+ policy and outcomes in Cambodia, Asia Pacific Viewpoint 56(1): 111-127.

Tsing, A.L. (2005) Friction: An ethnography of global connection, Princeton, N.J.: Princeton University Press.

Weaver, S. (2015) A practitioner perspective On REDD: Commercial challenges in project-based rainforest protection financing in the Asia Pacific Region, Asia Pacific Viewpoint 56(1): 140-152. 